\title{
Scale-up Synthesis of Diallyl \\ Phthalate Prepolymer
}

Bendix Kansas City Division

BDX-613-3147

By D. A. Carey

Department 814

Distributed October 1984

Quarterly Report on 705438

FY84-4 July to September 1984

G. K. Baker, Project Leader
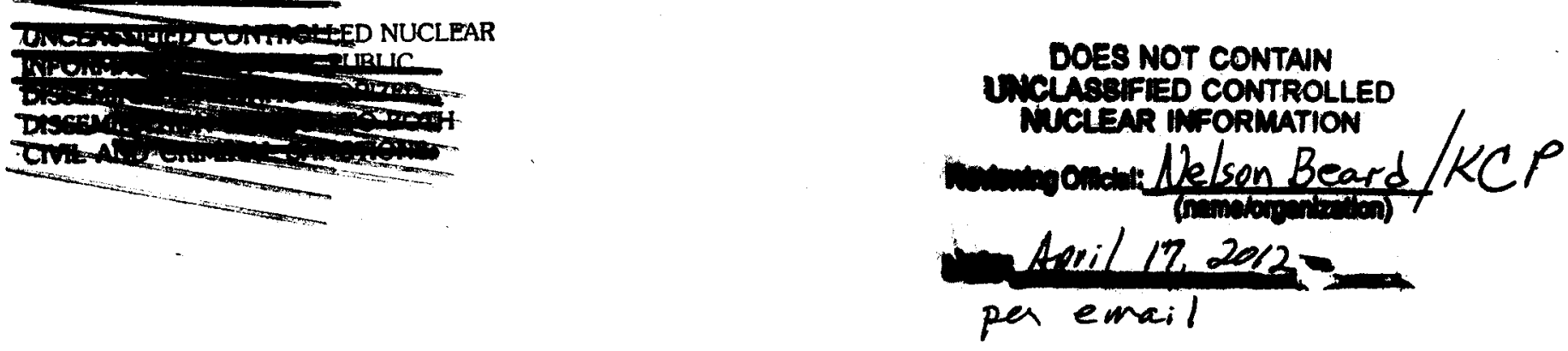

Woreng pumicolanmmitrow

THIS DOCUMENT CONMM:M INFORMATION THAT MAY BESEOJECT TO

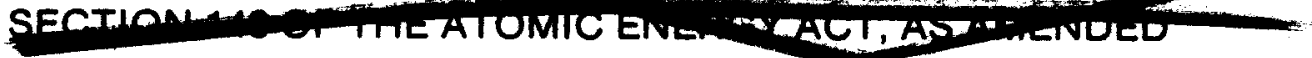

PATENT CAUTION

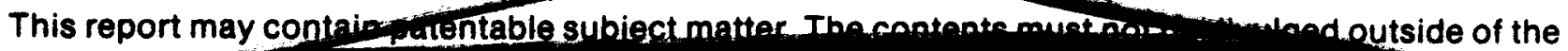

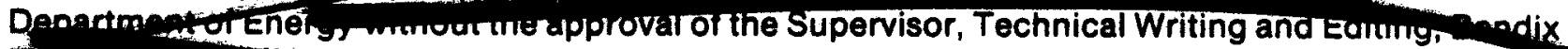

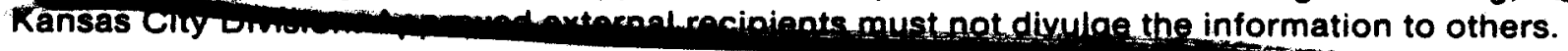

Prepared for the United States Department of Energy Under Contract Number DE-AC04-76-DP00613.

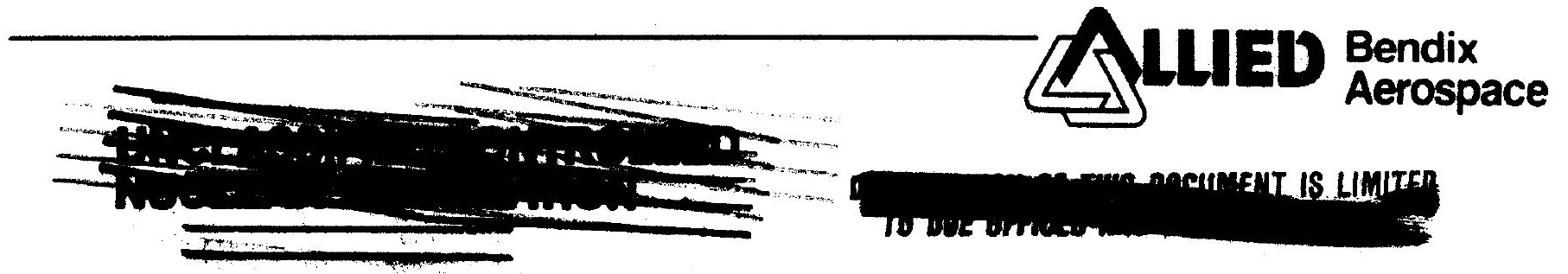




\section{DISCLAIMER}

This report was prepared as an account of work sponsored by an agency of the United States Government. Neither the United States Government nor any agency Thereof, nor any of their employees, makes any warranty, express or implied, or assumes any legal liability or responsibility for the accuracy, completeness, or usefulness of any information, apparatus, product, or process disclosed, or represents that its use would not infringe privately owned rights. Reference herein to any specific commercial product, process, or service by trade name, trademark, manufacturer, or otherwise does not necessarily constitute or imply its endorsement, recommendation, or favoring by the United States Government or any agency thereof. The views and opinions of authors expressed herein do not necessarily state or reflect those of the United States Government or any agency thereof. 


\section{DISCLAIMER}

Portions of this document may be illegible in electronic image products. Images are produced from the best available original document. 
This report was prepared as an account of work sponsored by an agency of the United States Government. Neither the United States Government nor any agency thereof, nor any of their employees, makes any warranty, express or implied, or assumes any legal liability or responsibility for the accuracy, completeness, or usefulness of any information, apparatus, product, or process disclosed, or represents that its use would not infringe privately owned rights. Reference herein to any specific commercial product, process, or service by trade name, trademark, manufacturer, or otherwise does not necessarily constitute or imply its endorsement, recommendation, or favoring by the United States Government or any agency thereof. The views and opinions of authors expressed herein do not necessarily state or reflect those of the United States Government or any agency thereof.

By D. A. Carey

Department 814

BDX-613-3147

\section{Distributed October 1984}

Quarter1y Report on 705438

FY84-4 July to September 1984

G. K. Baker, Project Leader

Project Team:

D. A. Carey

L. E. Lacy

C. S. Landis

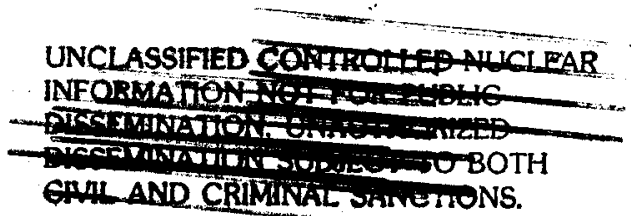

\section{Reviewed by:}

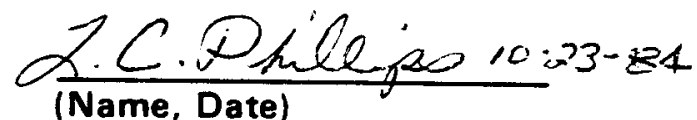

Jecurity Casis. AnaLiot

(Title)
This report contains information of a preliminary nature and installation. It is subject to revision or correction and therefore

confide represent a final report. It is passed to the recipient in

Thent the approval of the originacted or further disclosed

Technical Information Center, Oak Ridge, TN 37830. 
SCALE-UP SYNTHESIS OF DIALLYL PHTHALATE PREPOLYMER

BDX-613-3147, UNCLASSIFIED Quarter1y Report, Distributed October 1984

Prepared by D. A. Carey, D/814, under 705438

This project was initiated to develop processes for the synthesis of dially 1 phthalate (DAP) prepolymer in the Bendix Chemical Polymer Facility. Thus far, five scale-up reactions have been carried out in a 100-gallon reactor and fourteen have been conducted in the 15-gallon resin kettle. The synthesis of diallyl isophthalate prepolymer (DAIPP) was also investigated; eight scale-up reactions of this prepolymer have been carried out. Aging studies on DAIPP were also conducted.

$\mathrm{RM}: \mathrm{cmp}$

$\operatorname{dtr} 52 / \mathrm{m}$

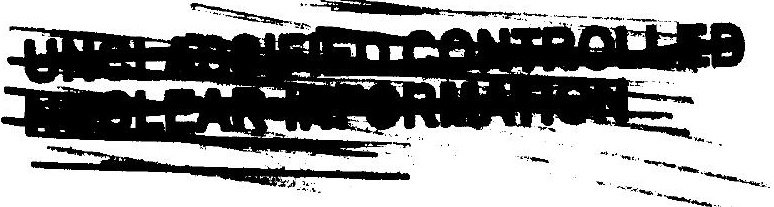


CONTENTS

Section

Page

SCOPE AND PURCHASE . . . . . . . . . . . . . . . . . .

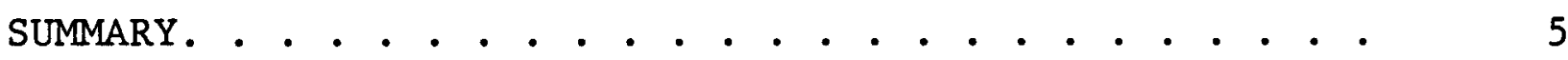

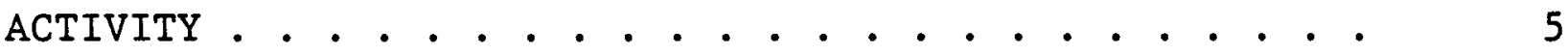

Synthesis of Diallyl Phthalate Prepolymer (DAPP) . . . 5

Scale-up of Prepolymer Recovery Using Methanol Extraction . . . . . . . . . . . . . . . 6

Solid DAIPP Aging Studies. . . . . . . . . . . . . 6

Mound Facility Characteristics of DAIPP Molding

Compounds. • . . . . . . . . . . . . . . . . 7

CONCLUSIONS . . . . . • . . . . . . . . . . . . 8

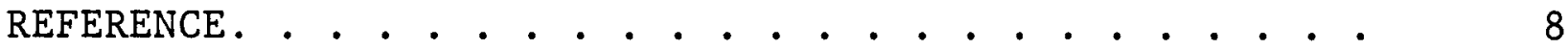

DISTRIBUTION • • • • • • • • • • • • • • • • . 15 


\section{TABLES}

Number

Page

Molecular Weights of DAIPP Without and With Stabilizer Aged at $50^{\circ} \mathrm{C}$. . . . . . . .

Molecular Weights of DAIPP Without and With Stabilizer Aged at $40^{\circ} \mathrm{C}$. . . . . . . .

Molecular Weights and Monomer Contents of Diallyl Isophthalate Prepolymer (DAIPP)

DAIPP and DAPP Molding Compound Formulations

Thermal Properties of Fiberglass DAIPP and DAPP Molding Compounds

Physical Properties of Fiberglass DAIPP and DAPP Molding Compounds . . . . . . .

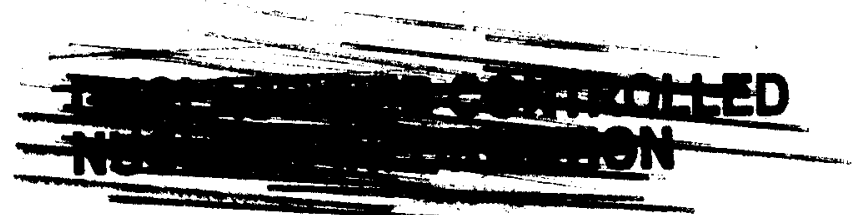


The purpose of this project is to develop scale-up processes for the synthesis of diallyl phthalate prepolymer (DAPP) in the Bendix

Chemical Polymer Facility. A specific objective is to synthesize a prepolymer that is a replica of Dapon 35, which is no longer

commercially available in the United States, in order to support the WR production requirements of Bendix, Monsanto Research Corporation, Mound Facility, and Martin Marietta Corporation, the Oak Ridge Y-12 Plant.

\section{SUMMARY}

Two scale-up syntheses of diallyl phthalate prepolymer (DAPP-26 and 27) were conducted in a 100-gallon resin kettle. These prepolymer reaction products were used to establish the feasibility of using the recently installed rotary vacuum vessel to recover large quantities of DAPP. The first batch of prepolymer was overheated during the drying process by frictional heat from the agitator. Examination of this prepolymer indicated that it was slightly crosslinked. In the second batch (DAPP-27) 117 pounds of diallyl phthalate prepolymer was successfully extracted. This was accomplished with the aid of $1500 \mathrm{ppm}$ of stabilizer (A02246). Also, during this quarter a 50/50 blend (recovered/virgin) of monomer was used to produce a batch of DAPP which had similar chemical properties to that made from $100 \%$ virgin monomer.

The evaluation of stabilizers (Irganox 1010 and A02246) for solid diallyl isophthalate prepolymer (DAIPP) was completed during this quarter. Both stabilizers have improved the stability of DAIPP; however, no marked difference was observed in the degree of stability obtained from either stabilizer. Mound Facility has obtained preliminary favorable test results from fiber glass molding compound made on a laboratory scale using DAIPP resin produced at Bendix Chemical Polymer Facility. The DAIPP molding compound showed enhanced thermal and physical properties as compared to DAPP molding compound. Mound is presently evaluating a larger batch of DAIPP which was made from a blend of batch 21 and batch 23B.

\section{ACTIVITY}

Synthesis of Diallyl Phthalate Prepolymer (DAPP)

In the synthesis of diallyl phthalate prepolymer, only approximately 25 percent of diallyl phthalate monomer is converted to prepolymer. The remaining 75 percent of unreacted monomer is removed by methanol extraction. During the previous quarter, the rotary vacuum vessel was 
used as a still to remove the methanol from the monomer-methanol solution. One scale-up reaction (DAPP-28) was prepared in the 15-gallon resin kettle using a 50/50 (recovered/virgin) monomer blend. The diallyl phthalate prepolymer obtained was similar to prepolymer which was made from virgin monomer. Also, when compared to earlier batches synthesized from virgin monomer, no noticeable time change in the polymerization rate was observed.

In addition, two scale-up reactions (DAPP-26 and 27) were prepared in the 100-gallon resin kettle. The purpose of the scale-up syntheses was to produce prepolymer for a large scale DAPP extraction evaluation. The prepolymer reactions were terminated when the viscosity of the reaction mixture was 50 centipoise at a temperature of $65^{\circ} \mathrm{C}$. The purpose of this viscosity target was twofold: Firstly, reaction mixture under this condition contains DAPP product which has the desired bimodal molecular weight distribution; and secondly, this condition also allows a "wide operational window" which would accommodate some further polymerization during the extraction and drying processes without any detrimental effect on the final product.

\section{Scale-up of Prepolymer Recovery Using Methanol Extraction}

The solid prepolymer was separated from the monomer in the reaction mixture by extracting the monomer with methanol in three stages. Approximately 600 pounds of diallyl phthalate reaction product was placed in the rotary vacuum vessel. Seventy-three gallons of methanol were added and the mixture agitated at $37^{\circ} \mathrm{C}$ for 30 minutes. The mixture was cooled to room temperature and allowed to settle overnight. During this time, two phases were formed. One was methanol-monomer phase and the other was the prepolymer phase. The prepolymer phase had some monomer still not extracted. The upper layer (methanol-monomer phase) was syphoned from the reactor. The process was repeated in the second and third stages with the same amount of methanol as in the first stage; however, the extraction temperature was raised to $65^{\circ} \mathrm{C}$ in the second and the third stages. After the third extraction and the removal of the methanol-monomer phase, the prepolymer was vacuum dried in the same vesse1 at $65^{\circ} \mathrm{C}$. Batch 26 (DAPP-26) was agitated during the drying process. Unfortunately, frictional heating increased the temperature of the prepolymer significantly and this resulted in the formation of a crosslinked product. Batch 27 (DAPP-27) was dried, but the agitator was used only to grind the prepolymer to a powdered form. That is, the agitator was used only after the product was considered fairly dried. Also, 1500 ppm of A02246 stabilizer was added prior to the drying process. This time, the prepolymer product was acceptable. The total yield of DAPP after grinding was 117 pounds, and the final product after drying had 5.0 percent residual monomer and a $\overline{\mathrm{M}}_{\mathrm{w}}$ of 31,000 .

Solid DAIPP Aging Studies

As djscussed in an earlier report, DAIPP is apparently less stable than DAPP $(1)$. Therefore, an investigation to improve the stability of DAIPP was initiated. Two uni-modal molecular weight prepolymer batches (DAIPP-23A and 24) were manufactured for this evaluation. Since DAIPP-23A. 
and DAIPP-24 had similar properties, they were combined to provide the desired quantity of material for the stabilization investigation. The aging studies were conducted at $40^{\circ} \mathrm{C}$ and $50^{\circ} \mathrm{C}$ using Irganox 1010 and A02246 as the stabilizers at different concentration.

The molecular weight of the samples was monitored as a function of time and temperature. The information obtained from this evaluation is tabulated in Tables 1 and 2. For comparison purposes, earlier work done with unstabilized prepolymer is also included in the tables. As can be seen, samples which had stabilizers underwent a slower rate of solid state polymerization. As would be expected, the prepolymer aged at $40^{\circ} \mathrm{C}$ showed less solid state polymerization than those samples aged at $50^{\circ} \mathrm{C}$. The $\overline{\mathrm{M}}_{\mathrm{w}}$ measurements, however, did not differentiate between the type and level of stabilizer used. On the other hand, the $\overline{\mathrm{M}}_{\mathrm{w}}$ measurements clearly indicate that either stabilizer would be effective in retarding the solid state polymerization. Actually, after 34 days at $50^{\circ} \mathrm{C}$, it is essentially impossible to measure the molecular weight of the sample without stabilization. At this point, the DAIPP had crosslinked.

\section{Mound Facility Characterization of DAIPP Molding Compounds}

The three samples of DAIPP (DAIPP-21AC, 18BC, and $21 / 23$ blend) sent to Mound were selected because of the wide ranges in molecular weights. Table 3 shows the molecular weights and monomer content for all samples. of those samples, Mound has recently evaluated DAIPP-21AC on a laboratory scale. The formulations used in preparing the molding compound are shown in Table 4 along with an Osaka diallyl phthalate prepolymer used as a comparison. The formulations used are comparable in all respects, except that a lower amount of monomer was used with DAIPP-21AC, due to its higher initial monomer content.

Differential Scanning Calorimetry (DSC) and Thermogravimetric Analyses (TGA) were used to determine thermal properties of the two molding compounds after "B-Staging" (See Table 5). Mound determined that the DSC curing properties of the two molding compounds were similar; however, TGA data showed the DAIPP molding compound exhibits a higher decomposition onset and a slightly higher inflection point which is interpretated as an inherently better thermal stability. The physical properties of both molding compounds were also examined. The results are given in Table 6 . Based on this limited evaluation, the DAIPP molding compound produced parts which surpassed all the properties required for certification for DAPP molding compound. The heat distortion tests (HDT) results were of particular interest to Mound personnel because the DAIPP showed enhanced thermal stability over DAPP as already determined. This enhanced thermal stability is probably due to an inherent difference in the basic structure of this prepolymer. These initial results with DAIPP are encouraging and work with this prepolymer will be continued.

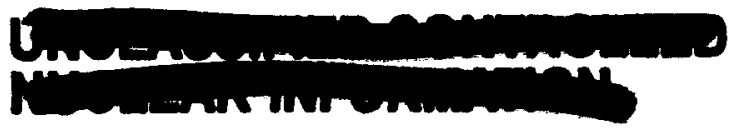




\section{Conclusions}

Large quantities of DAPP can be produced using the recently installed process equipment for handling solid polymers in the BKC Chemical

Polymer Facility. It has been demonstrated that A02246 or Irganox 1010 can be used to retard the solid state polymerization of diallyl isophthalate prepolymer. Initial evaluations conducted at Mound on a molding compound using DAIPP resin have shown enhanced thermal and physical properties as compared to DAPP molding compound.

Planned Activity for Next Quarter

Three hundred and fifty pounds of diallyl phthalate prepolymer will be produced in BKC Polymer Chemical Facility for Monsanto Research

Corporation, Mound Facility, to evaluate on a production-type scale.

\section{REFERENCE}

1. D. A. Carey, Scale-up Synthesis of Diallyl Phthalate Prepolymer, Quarterly Report, Bendix Report Number BID-A542, December 1983.

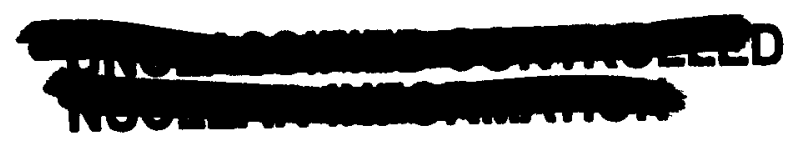


TABLE 1. MOLECULAR WEIGHTS OF DAIPP WITHOUT AND WITH STABILIZER AGED AT $50^{\circ} \mathrm{C}$

Stabilizer Type

without stabilizer

without stabilizer

without stabilizer

without stabilizer

Irganox 1010

Irganox 1010

Irganox 1010

Irganox 1010

Irganox 1010

Irganox 1010

Irganox 1010

Irganox 1010

A02246

A02246

A02246

A02246

A02246

A02246

A02246

A02246
Concentration Weight Percent

0

0

0

0

0.5

0.5

0.5

0.5

0.06

0.06

0.06

0.06

0.5

0.5

0.5

0.5

0.06

0.06

0.06

0.06

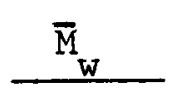

$\overline{\mathrm{M}}_{\mathrm{n}}$

Aging

Time, Days

$\begin{array}{rrr}17,271 & 5,616 & 0 \\ 19,099 & 5,879 & 6 \\ 96,336 & 7,580 & 27 \\ 195,715 & 7,680 & 34\end{array}$

20,321

31,631

33,871

42,585

7,751

8,992

8,949

9,670

20,782

33,201

37,909

43,751

7,751

8,651

9,455

9,720

$20,650 \quad 6,981$

8,731

8,066

9,060

36,740

43,851

21,320

7,321

9,501

9,560

40,061

44,850

9,963
0

6

34

6

27

34

77

6

27

34

77

6

27

34

77

6
27
34
77 
TABLE 2. MOLECULAR WEIGHTS OF DAIPP WITHOUT AND WITH STABILIZER AGED AT $40^{\circ} \mathrm{C}$

\begin{tabular}{|c|c|c|c|c|}
\hline Stabilizer Type & $\begin{array}{r}\text { Concentration } \\
\text { Weight Percent } \\
\end{array}$ & $\overline{\mathrm{M}}_{\mathrm{w}}$ & $\overline{\mathrm{M}}_{\mathrm{n}}$ & $\begin{array}{c}\text { Aging } \\
\text { Time,Days }\end{array}$ \\
\hline $\begin{array}{l}\text { without stabilizer } \\
\text { without stabilizer } \\
\text { without stabilizer }\end{array}$ & $\begin{array}{l}0 \\
0 \\
0\end{array}$ & $\begin{array}{r}19,203 \\
26,954 \\
105,161\end{array}$ & $\begin{array}{l}6,384 \\
6,412 \\
9,872\end{array}$ & $\begin{array}{l}13 \\
55 \\
94\end{array}$ \\
\hline $\begin{array}{ll}\text { Irganox } & 1010 \\
\text { Irganox } & 1010 \\
\text { Irganox } & 1010\end{array}$ & $\begin{array}{l}0.5 \\
0.5 \\
0.5\end{array}$ & $\begin{array}{l}19,301 \\
22,156 \\
31,988\end{array}$ & $\begin{array}{l}7,561 \\
7,050 \\
8,971\end{array}$ & $\begin{array}{l}13 \\
55 \\
94\end{array}$ \\
\hline $\begin{array}{ll}\text { Irganox } & 1010 \\
\text { Irganox } & 1010 \\
\text { Irganox } & 1010\end{array}$ & $\begin{array}{l}0.06 \\
0.06 \\
0.06\end{array}$ & $\begin{array}{l}21,300 \\
21,583 \\
33,802\end{array}$ & $\begin{array}{l}6,560 \\
7,693 \\
9,594\end{array}$ & $\begin{array}{l}13 \\
55 \\
94\end{array}$ \\
\hline $\begin{array}{l}\text { A02246 } \\
\text { A02246 } \\
\text { A02246 }\end{array}$ & $\begin{array}{l}0.5 \\
0.5 \\
0.5\end{array}$ & $\begin{array}{l}20,356 \\
22,122 \\
32,949\end{array}$ & $\begin{array}{l}6,970 \\
7,352 \\
9,884\end{array}$ & $\begin{array}{l}13 \\
55 \\
94\end{array}$ \\
\hline $\begin{array}{l}\mathrm{A} 02246 \\
\mathrm{~A} 02246 \\
\mathrm{~A} 02246\end{array}$ & $\begin{array}{l}0.06 \\
0.06 \\
0.06\end{array}$ & $\begin{array}{l}20,681 \\
23,982 \\
34,721\end{array}$ & $\begin{array}{l}7,009 \\
6,958 \\
9,771\end{array}$ & $\begin{array}{l}13 \\
55 \\
94\end{array}$ \\
\hline
\end{tabular}

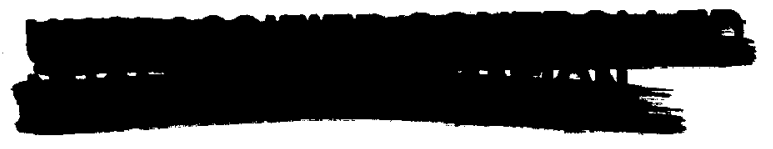


TABLE 3. MOLECULAR WEIGHTS AND MONOMER CONTENTS

OF DIALLYL ISOPHTHALATE PREPOLYMER (DAIPP)

\begin{tabular}{|c|c|c|c|c|c|}
\hline Prepolymer & Type of MW Distribution & $\bar{M}_{w}$ & $\overline{M_{H}}$ & MWD & $\begin{array}{r}\text { Monomer, } \\
\text { Wt. } \%\end{array}$ \\
\hline $\begin{array}{l}\text { BKC-DAIP } \\
21-A C\end{array}$ & Bi-modal & 63,700 & 7,300 & 8.76 & 5.6 \\
\hline $\begin{array}{l}\text { BKC-DAIP } \\
21-D\end{array}$ & $\begin{array}{l}\text { Bi-modal with high } \\
\text { mol. wt. shoulder }\end{array}$ & 143,400 & 7,600 & 18.95 & 4.4 \\
\hline $\begin{array}{l}\text { BKC-DAIP } \\
18-\mathrm{BC}^{\mathrm{a}}\end{array}$ & Tri-modal & 542,600 & 9,200 & 59.1 & 5.1 \\
\hline $\begin{array}{l}\text { BKC-DAIP } \\
2123^{b}\end{array}$ & Bi-modal & 43,750 & 7,700 & 5.69 & 3.2 \\
\hline $\begin{array}{l}\text { Osaka-o-DAP } \\
29061-\mathrm{RT} 1\end{array}$ & Bi-modal & 45,600 & 6,600 & 6.89 & 2.8 \\
\hline
\end{tabular}

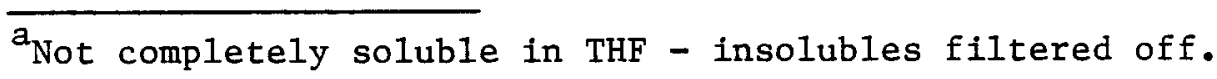

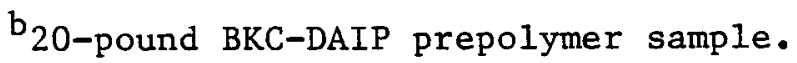


TABLE 4. DAIPP AND DAPP MOLDING COMPOUND FORMULATIONS

Materials

Formulation No.

\section{Prepolymer}

Type

Wt.\%

\section{Fiber Reinforcement}

\section{Type}

Wt.\%

\section{Other}

$\begin{array}{lcc}\begin{array}{l}\text { Hydrous Alumina } \\ \text { Techfil 106) }\end{array} & 10.0 & 10.0 \\ \begin{array}{l}\text { Kaolin Clay } \\ \text { (ASP-400) }\end{array} & 1.0 & 1.0 \\ \text { O-DAP Monomer } & 1.5 & 3.0\end{array}$

\footnotetext{
Remainder - Calcium stearate, t-Butyl perbenzoate, hydroquinone

Procedure - Dissolve prepolymer in acetone in 2-gallon sigma blade mixer; add other materials; remove acetone by vacuum and mill on 2 -roll mill to $100^{\circ} \mathrm{C}$, "B-Stage" $/ 15-45 \mathrm{~min} . / 100^{\circ} \mathrm{C}$, vented oven.
}

$$
\text { o-DAPP(Osaka) }
$$

37.0 
TABLE 5. THERMAL PROPERTIES OF FIBERGLASS DAIPP AND DAPP MOLDING COMPOUNDS

\begin{tabular}{lcc} 
DSC Results & $\begin{array}{c}\# 625 \\
\text { (DAIPP-FG) }\end{array}$ & $\begin{array}{l}\text { (DAPP-FG) } \\
\text { (DAP }\end{array}$ \\
\hline
\end{tabular}

\section{Exotherm}
Peak, ${ }^{\circ} \mathrm{C}$
$H_{R}, J / g$
165.9
97.5
164.8
94.3

Endotherm

$$
\begin{array}{r}
\text { Peak, }{ }^{\circ} \mathrm{C} \\
\text { H, J/g }
\end{array}
$$

$$
\begin{array}{rr}
103.7 & 113.8 \\
0.6 & 2.75
\end{array}
$$

TGA Results

1) Wt.\% Volatiles (to $300^{\circ} \mathrm{C}$ )

$$
1.6 \quad 2.2
$$

(inc1. monomer/catalyst)

2) Polymer Decomposition

Extrapolated Onset

377

407.5

348

Inflection

Wt.\%

44.6

400.4

45.0

Wt.\% Residue at $900^{\circ} \mathrm{C}$

53.3

53.4 
TABLE 6. PHYSICAL PROPERTIES OF FIBERGLASS DAIPP AND DAPP MOLDING COMPOUNDS

Results and Number of Test Specimens

Minimum

Acceptable \#625\% \#609

Physical Test

$\underline{\text { Value }} \quad \underline{\text { (DAIPP-FG) }}$

$\underline{(\mathrm{DAPP}-\mathrm{FG})}$

Rheometer

Min. Torque, in.-1b.

$\%$ of Max. $/ 3$ min.

4-15

$90 \%$

4.5

$99 \%$

$3.5-4$

94

Tensile Strength

1b./in..$^{2}$ - ASTM D-651

4500

7672 (2)

6797 (3)

Notched Izod

Impact Strength

ft.-lb./in. notch

0.30

0.594

(2)

0.487

(2)

ASTM D-256A

Compressive Strength
lb./in. ${ }^{2}$ - ASTM D-695
16,000
18,420 (4)
17,150
(2)

Arc Resistance

sec., ASTM D-495

115

125 (4)

$122(5)$

Heat Distortion Temp.

${ }^{\circ} \mathrm{C}$, ASTM D-648

160

180 (1)

164 (1)

Mesa Spiral

Flow, in.

varies

20 